\title{
台湾地区乡村规划政策的演进研究 基于经济社会变迁视角
}

\author{
On the Transition of Taiwan's Rural Planning Policy: A Perspective of Economic and Social Changes
}

蔡宗翰 刘娜 丁奇

Tsai Chung Han, Liu Na, Ding Qi

摘要: 乡村规划的政策目标通常会受到整体经济和社 会发展的影响。本文基于经济社会变迁的视角, 分析 研究台湾地区乡村规划政策目标转变的历程, 即从开 始时的“农业支持工业”、“乡村支持城市”、“乡村城 市并重”目标, 到近期的“乡村城市互补”、“城市乡 村各善其长”的规划目标转移; 通过分析台湾地区各 个时期乡村规划目标和规划手段的变化, 探究乡村规 划政策变迁的影响因素。本文旨在为大陆地区制定乡 村规划政策提供借鉴。

Abstract: Rural plan is not only the blueprint of but also policy objective for rural development, which is always influenced by the macroeconomic and social development. In this paper, we analyze the transition of Taiwan's rural planning policy under the general economic and social changes, moving from agricultureto-industry nurturing and rural-to-urban supporting, to rural-urban balancing, and to urban-rural integrating and urban-rural strengthening. The subject of this research is to discover factors influencing the transition of rural planning policy through analyzing changes of planning targets and patterns in every period. It is hoped that the paper would provide some hints for Mainland China in developing rural planning policy.

关键词: 乡村规划; 政策演进; 经济社会变迁

Keywords: Rural Planning; Policy Transition;

Economic and Social Changes

作者: 蔡宗翰, 北京建筑大学经管学院副教授, 住建部 村镇建设司乡村规划研究中心村庄发展与土地研 究所所长。caizonghan@bucea.edu.cn

刘娜, 北京建筑大学经管学院硕士研究生, 住建 部村镇建设司乡村规划研究中心村庄发展与土地 研究所助理研究员

丁奇 (通信作者), 北京建筑大学建筑与城市规划 学院, 住建部村镇建设司乡村规划研究中心主任。 dingqi@bucaea.edu.cn

\section{引言}

台湾地区的乡村发展经验告诉我们, 乡村规划政策与整体经济社会环 境之间有着极强的交互影响作用。例如, 台湾于 1953 年制定了 “第一期台 湾地区经济建设四年计划” ${ }^{[1]}$, 随之乡村规划的编制也开始起步, 但此时的 乡村规划目标都是以服务城市服务工业为主的目的挂帅；1960 年代开始， 台湾乡村规划政策转变, 显示着台湾地区经济基础由单纯的农业经济转向 工业经济; 而 1970 年代出口导向的经济政策带动经济高速发展, 导致了乡 村工业区的设置；1980 年代早期，由于贸易顺差持续增长、金额持续扩大， 使得生产者与消费者对消费型服务业的需求大幅提升；1980 年代中期以后， 劳动密集型加工出口工业逐渐丧失比较优势, 导致民间投资意愿低落, 经 济发展出现困境。当时台湾地区乡村规划编制的目标是 “一切为了工业和 城市发展”, 显然这一目标下的乡村规划已经走到了尽头, 必须要转型。到 1990 年代后, 台湾的服务经济快速上升, 一直到 1992 年台湾地区人均收人 超过 1 万美元 ${ }^{[2]}$ 时, 乡村规划以 “提升乡村生活、生态质量” 及 “环境综 合利用” 等为主要目标。特别是台湾地区于 2002 年加人 WTO 后, 与经济 发展政策并行的乡村规划政策也意在使市场发挥更大的作用, 包括较少运 用政府 “法令”, 努力强化市场机制调节乡村产业和社区的综合发展 ${ }^{[3,4]}$ 。至 2005 年, 服务业在地区生产总值中占到了 $73.6 \%$; 同期乡村消费型服务业 的比重也逐年增长, 此时乡村规划的目标开始针对乡村服务业, 也就是乡 村 1.5 产业、2.5 产业发展转型 ${ }^{[5]}$ 。

2009 年后, 台湾地区已经进人后工业化社会, 产业经济对乡村发展的 作用逐渐减弱, 即不再仅仅以乡村经济增长作为发展指标, “乡村社区总体 营造” 成为乡村规划的目标和手段。笔者认为, 在经济社会变迁的视角下研 究台湾地区乡村规划政策的演进, 有助于深人观察台湾地区的社会发展, 理 解乡村规划政策变迁的前因后果, 进而汲取对大陆地区乡村规划的借鉴意义。

\section{1 台湾地区的乡村规划}

乡村规划作为乡村发展的目标导向和蓝图, 一直以来都是台湾地区乡 村发展的主要议题, 特别是以土地改革为主的乡村规划政策直接带动了乡 
村经济发展 ${ }^{[6]}$ 。1993 年以前的台湾, 一直将“土地”、“农 业”、“产业”的经济增长效益放在乡村规划目标的首位 ${ }^{[7]}$ 。 1994 年, 台湾地区颁布“社区总体营造计划”, 此后的乡村 规划突破了传统的乡村规划政策目标，规划手段由“自上而 下”的政府投人、政府试点等转为 “自下而上”的“乡村社 区总体区营造”; 同时汲取了前期乡村社区发展政策中的参 与性、在地性因素，政府的规划职能发生了“政策控制” 向 “提供政策服务” 的转变; 乡村规划从 “以土地为中心” 转 变为 “以人为中心” ${ }^{[8]}$ 。其后 2010 年 “乡村再生条例” 的制 定，又将乡村规划的重点从“三农问题”转向了“生活、生 产、生态”与“农民、农业、乡村” 融合的“三生共生、三 农共荣”。

通过以上对台湾地区乡村规划发展的纵览, 可以认为台 湾地区现今的乡村规划是 “乡村空间形态与乡村发展、乡村 生活”并重的乡村社区综合营造规划，包括了乡村经济发展 与创新、乡村社区培育、乡村生态永续、乡村文化的再发现 和再延续等内容。当今, 台湾乡村规划与城市规划的区别在 于乡村规划的 “后工业” 属性, 即乡村规划不再是工业化、 城市化的附庸和致力于提供服务, 而是走向突出乡村生态化、 农民生活化、农业在地化特色的蕴含 “乡愁” 的规划。

下文将乡村规划发展分为 1949-1993 年、1994-2008 年和 2009 年至今三个时期展开详细讨论。

\section{2 通过乡村土地改革政策奠定乡村发展基础 (1949-1993 年)}

从经济发展的规律来看, 1950 年代的台湾工业虽然在乡 村发展政策扶持下得到了发展，但这个时期的乡村规划目标 是推动农业产值的增加。到 1960 年时, 台湾地区农业产值占 GDP 的三分之一；1962 年, 农业产业提供了一半以上的就业 和出口 ${ }^{[3]}$ 。可以认为, 该时期的乡村规划政策是以发展农业 经济为核心目标。1976 年, 台湾地区人均 GDP 首超 1000 美

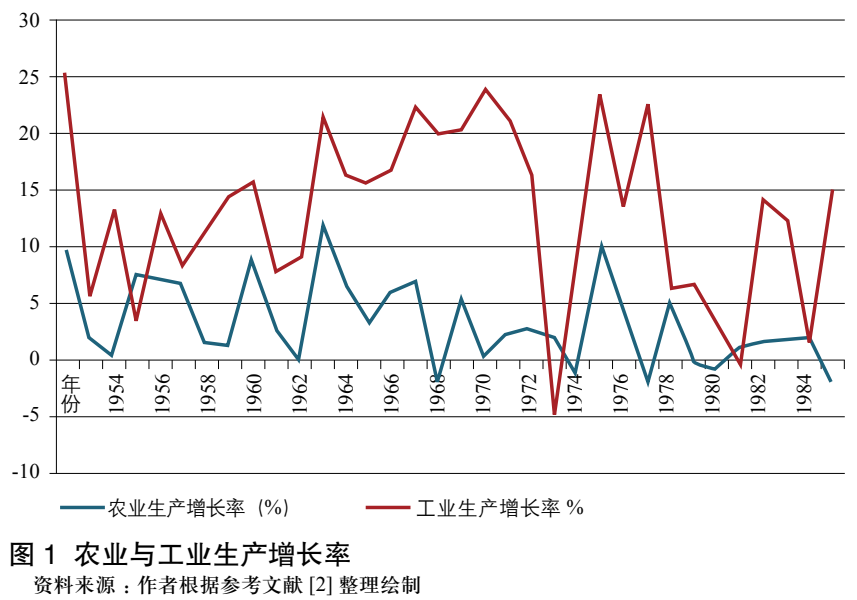

元, 1984 年首超 3000 美元。而自 1980 年代中期至 2000 年, 台湾地区人均 GDP 年均增长 1000 美元, 特别是自 1992 年 起, 台湾地区人均 GDP 超过 1 万美元, 正式进人了中等发达 经济体行列。在此期间, 台湾地区的乡村规划政策是围绕着 土地改革政策实施的一一两次土地改革的顺利完成是乡村发 展的基础, 它对整个台湾地区经济发展都发挥了举足轻重的 作用 ${ }^{[9]}$ 。以下从分析台湾地区的两次乡村土地改革政策人手, 对台湾地区乡村规划的政策历程作背景和影响分析。

\section{1 第一次土地改革（1949-1978 年）}

自 1949 年起, 台湾地区开始了第一次土地改革, 主要 分为三个阶段 : 三七五减租、公地放领、耕者有其田 ${ }^{[10]}$ 。本 次土地改革改变了佃农经济, 建立了自耕田制度; 在农业发 展上主要选择了外向型农业经济; 同时以促进农业持续快速 发展为规划目标, 实施了农业技术革新、农业机械应用和农 作物品种改良等措施。农业作为乡村规划的主要目标, 助力 了战后台湾地区经济的恢复。至 1964 年, 农业生产增长率 与工业发展增长率均达到峰值, 分别为 $11.9 \%$ 和 $21.2 \%$ (图 1)。 整体而言, 这一时期可谓实施了适度 “盘剥农业” 以培养工 业的乡村规划战略 ${ }^{[11]}$ 。

随着 1960 年代台湾地区经济的重心从农业转向工业生 产, “第三期经济建设四年计划（1961－1964 年)”将工业 生产置于农业生产之上, 以此作为乡村规划政策的主要目标, 导致了经济发展的不均衡一一在工业以双位数增长的同时, 农业产值出现了负增长。如 1969 年的工业增长率为 $19.8 \%$, 农业增长率则为 $-2 \%$ 。至 1973 年, 工业就业人口率首次超 过农业就业人口率（图 2)。

这一阶段的乡村规划政策主轴是：通过土地改革手段, 激活农村资源, 带动农业增长并为工业增长服务; 通过土 地、农业、教育等乡村发展政策措施来引导乡村资源向城市 转移、乡村人口向城市流动, 促使城市快速发展。台湾地区

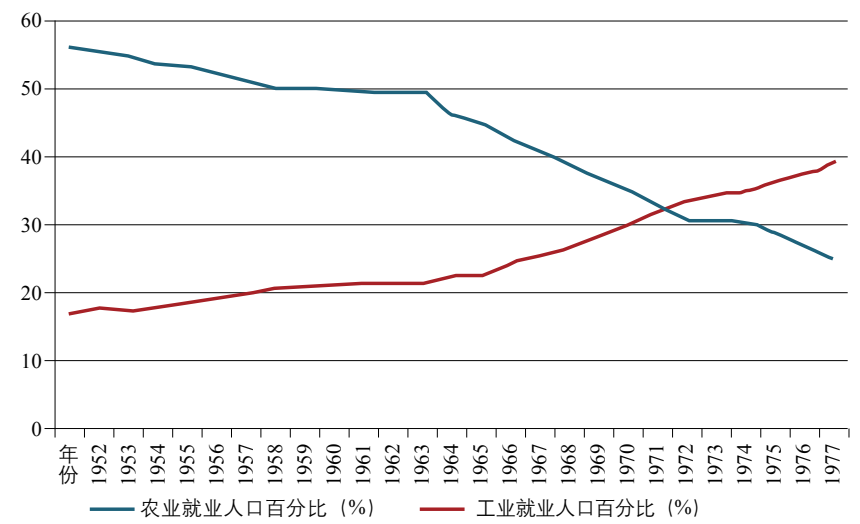

图 2 农业与工业就业情况 资料来源 : 作者根据参考文献 [3] 整理绘制 
1950 年的城市化率仅为 $24.07 \%$, 至 1970 年便大幅上升到了 $55.5 \%$ 。但乡村自身的发展相较于城市发展则处于劣势, 且 第一次土地改革后, 台湾地区南部以 “小农制” ${ }^{[12]}$ 为基础的 乡村已经不能适应农业机械化发展的需求, 乡村发展遭遇瓶 颈。至此, 针对存在的问题, 根据前期的经验启动了第二次 乡村土地改革。

\section{2 第二次土地改革（1979-1993 年）}

进人 1970 年代后, 新兴经济体如韩国、新加坡、台湾 地区、香港地区合称 “亚洲四小龙”, 成为世界经济发展的 亮点。而由于农产品的种植技术发展和新兴农业生产地如古 巴、泰国等地的开发, 造成国际市场上的传统农产品竞争加 剧, 台湾地区的 “米糖” 经济正式瓦解 ${ }^{[13]}$ 。因为台湾地区旧 有的小规模乡村经济在国际竞争中明显缺乏竞争力, 所以第 一次土地改革形成的以“小农制”为代表的农业生产方式亟 需改变, 新型农业亟待发展。这构成了本阶段乡村规划政策 调整的主因。新的土地改革政策包括废除对乡村土地兼并的 限制, 允许部分乡村土地自由流转, 扩大农业生产规模, 推 广和发展 “共同经营”、“专业区”、“委托代耕”等措施, 以 推动 “大农业”的发展。总之, 该阶段的乡村规划政策, 除 促进了农业的规模化发展外, 还清除了阻碍乡村土地集约利 用和市场化流转的制度性障碍, 为工业资本进人乡村地区、 以市场机制经营乡村土地创造了条件 ${ }^{[14]}$ 。

台湾地区乡村规划的结合具体实施措施包括：1982 年 的“第三期提高农民所得, 加强乡村建设方案”, 1984 年的 “加速基层建设, 增进农民福利方案”和发展 “精致农业” 的构想, 1985 年的“加速农业升级重要措施, 改善农业结构, 提高农民所得” 方案等; 以及 1995 年的通过规划后进行 “农 地释出方案”。该阶段的乡村规划措施强调 “调和城乡发展”、

“重视社会公平”和 “公共建设” 等; 在手段上则仍集中于 改革和政策调整, 如调整土地利用政策和农地利用政策, 调 整农业保护政策中的农业补助方向等, 希冀通过产业政策调 整来激活乡村经济。

\section{3 小结}

1950-1990 年代是台湾地区社会与经济高速发展的时 期, 两次土地改革夯实了乡村规划的经济基础。政府在第一 次土地改革中回笼的资金主要用于投资水利事业、建立自耕 农保护基金、提供农业贷款、实施土地重划及乡村基础设施 建设 ${ }^{\left[{ }^{9]}\right.}$, 它对此后的农业生产持续发展以至台湾地区整体经 济的发展都发挥了重要作用。此外, 两次土地改革一定程度 上克服了“小农制”生产方式的发展瓶颈，同时基于实际经 济发展需求, 开始通过规划进行土地整理, 对农村的基础生
产资源“农村土地” 按照发展阶段的需求进行了分析和整 理, 推动乡村工农业协调发展, 再一次促进了乡村经济的发 展。由于 1949-1993 年间以政府为主导, 乡村规划不支持 自主的社会力量, 在政府推动下的乡村发展工作范围包括了 公共设施建设、生产福利建设和精神伦理建设 ${ }^{[15]}$ 。但乡村政 策并没有关注乡村文化建设，乡村规划政策持续以“自上之 下”的方式执行，未赋予人民自主的规划权利。

\section{3 通过 “乡村社区总体营造政策” 促使乡村发展 转型（1994一2008 年）}

1994 年台湾地区行政当局拟定的“十二项建设计划” 中, “文建会”以“社区总体营造” 的政策为主题, 编列了 “充实乡镇展演设施计划”、“辅导美化地方传统文化建筑空 间计划” 等四项计划, 标志着台湾地区乡村社区总体营造的 正式启动 ${ }^{[16]}$ 。虽然 “乡村社区发展” 政策早已出现在乡村 规划政策中 ${ }^{[17]}$, 但本时期的“社区总体营造” 政策有别于早 先的“乡村社区发展”政策，因为乡村社区总体营造更关注 “自下而上”的参与性和在地性 ${ }^{[15]}$ 。乡村发展自此不再仅着 眼于乡村经济发展, 乡村规划政策跨越了“以土地为中心” 的经济效益取向, 实现了向“以人为中心”的社会效益取向 的转型。

\section{1 “社区总体营造” 的前期酝酿}

台湾地区自 1992 年人均 GDP 超过 1 万美元而正式进人 中等发达经济体行列后, 社会、经济发展速度开始趋缓, 并 展现出转型的趋势 (图 3)。促使乡村规划政策发生变化的 因素除经济制约外, 还包括社会运动、产业结构变化 ${ }^{[4]}$ 、城 乡关系变化等因素。城乡关系变化是指在城市与乡村的发展 过程中, 乡村人口逐渐外移, 城市人口迅速增长, 城市就业 人口增加; 同时乡村发展空心化、老龄化, 乡村社区认同感 缺乏, 传统文化与价值动摇, 乡村生产、生活、环境持续恶 化, 城乡矛盾加重 ${ }^{[17-19]}$ 。另外, 台湾地区乡村社区运动开始 发挥社会影响力, 乡村居民趋于积极参与政策制定, 成为影

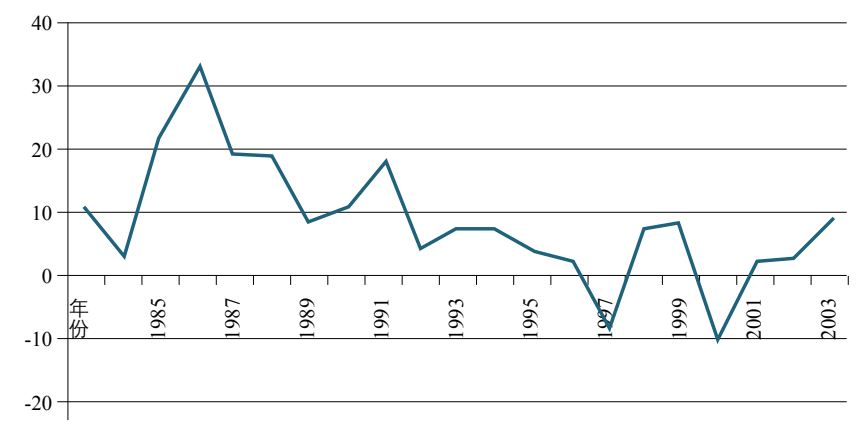

图 3 人均 GDP 增长率

资料来源 : 参考文献 [2] 
响乡村规划政策制定的重要因素。除此之外, 全球化资本冲 击、市场经济、信息技术、生态环境等因素也影响着乡村规 划政策的制定。这意味着台湾地区的乡村规划不再是墨守成 规的、空间专业的蓝图式规划，也不再是仅展现当地文化的 “展览”或刻板的“乡村活动”, 而是紧扣生活议题的 “空 间性” 和 “社会性” 的行动与计划 ${ }^{[20]}$ 。

\section{2 “社区总体营造” 的延伸}

乡村社区总体营造政策成为台湾地区乡村规划的主轴并 非一䟣而就。“社区总体营造”计划源自台北市政府提出的 “地区环境改造计划”, 该计划将 “居民参与”、“社区协力” 的概念融人城市规划的内容之中; 之后社区营造的理念逐步 扩展到了农村地区。1998 年, 台湾地区“经建会”的“扩 大内需求方案——创造城乡新风貌计划” 开始推动乡村环境 规划应由基层政府和乡村基层组织共同制定，而不再是由 上级政府直接制定规划。2001 年, 台湾政府通过了“创造 台湾地区城乡风貌”乡村总体发展规划, 该规划涵盖了“新 故乡社区营造” 的政策，在乡村规划编制中特别强调当地农 村社区居民的提案, 并鼓励各县市政府推广 “社区规划师” 制度，培养在地化乡村社区规划专业人员。其后的 2002 年, 台湾当局提出 “五年台湾地区经济社会发展总体规划”, 在 规划中明确将 “新故乡社区营造计划” 列为重点工作, 并成 为乡村规划编制和实施政策的主要依据, 该内容包括推动乡 村产业活化、乡村社区风貌营造、乡村文化资源创新活用等 七项规划编制主题, 28 项乡村规划具体实施手段, 社区营 造政策的概念正式进人乡村规划领域 ${ }^{[15]}$ 。2005 年, 因应前 期规划实施中的问题，政府出台了 “健康社区六星计划” 的 乡村规划编制政策, 要求乡村规划中必须体现产业发展、社 福医疗、社区治安、人文教育、环境景观、环保生态等六大 主题，但在编制手段上仍然延续 “在地性”、“参与性” 的概 念。2008 年, “磐石行动一一新故乡社区营造第二期计划” 通过, 将乡村社区总体营造规划加以系统化, 形成了完整的 乡村规划编制方法和编制要求，该计划要求乡村规划的目标 应该涵盖培养地方参与意识、重建地方认同感、形成政府与 民间组织的乡村发展协力伙伴关系等内容。

\section{4 通过 “乡村再生计划” 重燃乡村发展活力 ( 2009 年至今 )}

2009 年台湾当局根据前期乡村规划编制与实施的效果 和存在问题，制定了“乡村再生条例”。该条例延续了前期 “社区总体营造”政策中的乡村发展协力伙伴的编制方式, 同时配以“新农业运动” 的农业政策, 致力于开创“创力农 业、活力农民、魅力乡村”的农业新局面，以达成建立富丽
新乡村的目标, 将美化景观、社区服务、活化产业、留存文 化、教育培训等规划理念整合于 “生产、生活、生态” 的乡 村永续发展之中。

从政策推广的社会层面来看, 社区总体营造虽然是在城 市规划中实施的, 但在乡村规划中也已经产生了积极的指引 性作用。乡村规划中社区营造与城市规划中社区营造的区别 在于 : 前者首先要保障与协调乡村产业发展的 “经济事务”, 具有更强的经济属性; 而后者主要解决的是城市内部的 “公 共事务”, 具有相当强的政治属性 ${ }^{[21]}$ 。据此, 可以认为台湾 地区乡村规划的永恒主题是乡村产业永续发展, 包括重视充 分利用在地资源与经济特色, 并培育乡村人文力量。

\section{5 结论和启示}

通过对不同时期乡村规划政策的分析, 可以得出三个时 期的不同特点。

（1）第一个时期（1949-1993 年）即经济发展初期的 乡村规划特点

乡村发展政策仅被视为经济政策的一环, 乡村规划目 标主要是解决农业发展, 同时推进“农村服务城市、农业 服务工业” ; 实施策略上以“自上而下” 执行的土地整理政 策为主。该时期乡村规划的重点是促进农业生产, 农业服 务工业的经济性、政治性目标被视为首要目标; 而促进农 业发展、增进农民利益则为次要目标。利用乡村土地的“空 间交换价值” 和乡村配合城市工业发展亦为本时期乡村规 划的主要目的。

(2) 第二个时期（1994-2008 年）即经济转型时期的 乡村规划特点

此时的台湾地区因为经济、社会的剧烈变革而面临着产 业调整和社会意愿的转型, 乡村规划方式受之影响也发生了 转变。民众增强了对政策制定参与的权利要求、积极争取地 方民意支持的地方政治博弯、城乡经济发展矛盾的激化、地 方社区文化的缺失和生活环境危机等等, 新的需求导致了乡 村规划手段和目标的剧烈转变。“社区总体营造” 政策的出 台, 预示着乡村规划方式将由过去的 “自上而下” 向 “自下 而上” 方式转变, 同时也意味着乡村规划不仅要注重空间价 值, 更要注重其社会属性及公众参与。

（3）第三个时期（2009 至今）即经济发展平稳时期的 乡村规划特点

由于前期 “社区总体营造” 的 “自下而上”思想延伸到 了乡村规划之中, 同时乡村规划目标也从前期的土地综合整 治与农业发展转向了关注乡村社区的整体发展, 通过培育乡 村社区及乡村产业“在地化”扶植, 将“农民、农业、乡村” 与 “生产、生活、生态” 相融合, 凸显出乡村处发展鬼力之 
外, 还促进了城乡一体化和城乡各异化的发展。

纵观台湾地区乡村发展和规划政策变迁, 1994 年之前 是乡村发展配合经济发展, 乡村规划以土地整理为载体。然 而随着经济进人后工业化时代以及全球化背景下的经济发展 转型, 要求乡村规划在内容上必须包含地方特色与新经济增 长点; 同时 “自上而下” 的行政方式已经无法满足社会转型 的需求, 经济发展和政治改革只有落实到社区层次, 地区的 转型才能成功 ${ }^{[23]}$ 。

对比台湾地区的发展历史, 大陆现今的经济、社会发展 也已经进人转型时期, 乡村规划已经不能再固于通过乡村土 地整理和农业发展配套来满足农民、农业、乡村的发展。对 此, 我们可从台湾地区的相关经验中获取有益借鉴。Ⓟ

感谢同济大学赵民教授对本文的指导。

\section{参考文献}

[1] 台湾地区 (经济) 建设计划沿革 [EB/OL].[2016-01-14]. http://ebooks. lib.ntu.edu.tw/1_file/CEPD/2/001.pdf.

[2] 台湾地区统计资讯网 [DB/OL]. http://www.stat.gov.tw/mp.asp?mp=4.

[3] 李国鼎. 台湾地区经济发展背后的政策演变 [M]. 江苏：东南大学出版 社, 1993.

[4] 盛九元, 胡云华. 台湾地区的都市化与经济发展 [M]. 北京: 九州出版 社, 2009 .

[5] 贺涛. 台湾地区经济发展轨迹 [M]. 北京: 中国经济出版社, 2009.

[6] 吕宗盈, 林建元. 由制度面探讨台湾地区土地使用管理制度变迁之研 究 [J]. 建筑与规划学报, 2002, 3(2): 136-159.

[7] 孔宪法, 郭美芳. 台湾地区乡村空间发展规划之回顾 [C]//中国城市科 学研究会, 台湾地区都市计划学会, 宁波市人民政府. 2005 第十二届 海峡两岸城市发展研讨会论文集.中国城市科学研究会, 台湾地区都 市计划学会, 宁波市人民政府, 2005: 15.

[8] 黄源协, 萧文高, 刘素珍.从 “社区发展”到 “永续社区”一台湾 地区社区工作的检视与省思 [J]. 台大社工学刊, 2007(19): 87-132.

[9] 陈恩. 台湾地区的农业改革与农业政策 [J]. 台湾地区研究, 1996(3): 31-46.

[10] 朱桂香, 王炫, 樊万选. 中国台湾地区农业发展与《乡村再生条例》[J]. 世界农业, 2010(4): 63-68.

[11] 蔡天新, 陈国明. 现代台湾地区农业发展模式的历史考察 [J].中国经 济史研究, 2008(1): 129-137.

[12] 高兴松。小农制与台湾地区农业的发展 [J]. 台湾地区研究集刊, 1999(2): 31-38.

[13] 蔡宗翰, 张秀智. 台湾地区转型时期农地保护政策变迁分析 [J]. 苏州 大学学报 (哲学社会科学版), 2010(6): 78-82.

[14] 张子荣. 台湾地区历次土地改革与工业化的交互演进 $[\mathrm{J}]$. 人民论坛, 2014(34): 173-175.

[15] 曾旭正.从社区发展到社区营造 [C]//台湾社区营造协会. 落地生根一 台湾地区社区营造的理论与实践.台北: 唐山出版社, 2014: 5-18.

[16] 丁康乐, 黄丽玲, 郑卫. 台湾地区社区营造探析 [J]. 浙江大学学报 (理 学版), 2013(6): 716-725.

[17] 台湾地区社区发展工作纲要 [EB/OL]. [2016-01-14]. http://www.mohw. gov.tw/MOHW_Upload/doc/\%E7\%A4\%BE\%E5\%8D\%80\%E7\%99 $\%$ BC\%E5\%B1\%95\%E5\%B7\%A5\%E4\%BD \%9C\%Е7\%B6\%B1\%Е8 \%A6\%81_0046648002.pdf.

[18] 汤韵. 台湾地区城市化发展及其动力研究 [M]. 浙江: 浙江大学出版社, 2011.
[19] 韩昱, 郑启五.台湾地区人口省内迁移的现状及其影响分析 [J]. 当代 经理人, 2006(2): 4-5.

[20] 刘克智, 董安琪. 台湾地区都市发展的演进一一史的回顾与展望 [J]. 人口学刊, 2013(26): 1-25.

[21] 喻肇青. 社区行动计划与参与式社区工作坊 [C]//台湾地区社区营造 协会. 落地生根一一台湾地区社区营造的理论与实践. 台北: 唐山出 版社, 2014: 5-18.

[22] 李丁赞. 社区营造与公民社会 $[\mathrm{C}] / /$ 台湾社区营造协会. 落地生根— 台湾地区社区营造的理论与实践. 台北: 唐山出版社, 2014: 119-40.

[23] 黄丽玲. 新国家建构中社区角色的转变——社区共同体的论述分析 [D]. 台北: 台北大学建筑与城乡研究所硕士论文, 1995.

[24] 李永展. 社区组织运作 [C]//社区营造协会. 落地生根——台湾地区社 区营造的理论与实践.台北: 唐山出版社, 2014: 57-94.

(本文编辑：王枫)

(上接29页)

本文受到上海市城乡规划学科高峰计划及上海同济城市规 划设计研究院和同济大学建筑设计院的支持, 感谢赵民教授对 本文所做的工作。

\section{参考文献}

[1] 国务调整室.对外援助改善综合措施 [R]. 韩国, 2005.

[2]朱东周, 金鹤基, 金锡焕, 金桂焕。发达国家 ODA 援助实情分析与韩 国的对外援助战略 [R]. 韩国, 2009.

[3] 朱东周, 车文中, 权栗. 建立韩国特色的 ODA 模式 [R]. 韩国: 产业研 究院, 2012.

[4] 国务调整室内部资料 [R]. 韩国, 2015.

[5] 新村运动 ODA TF 组会议材料 [R]. 韩国 : 总理办公室发展合作政策官 室, 2012 .

[6] 金二基. 关于农村振兴厅的国际农业发展合作项目的历史及其特点研 究 [D]. 首尔大学硕士论文, 2000.

[7] 林衡白. 新村运动在非洲的政府援助（ODA）运用方向 [J]. 韩国区域 发展学会期刊, 2011, 23(2).

[8] 新村运动中央会. 2009 年新村教育成果报告 [R]. 韩国, 2010 .

[9] 行政安全部国际行政发展服务中心内部资料: 第三节“资源重构” [R]. 韩国, 2012 .

(本文编辑：许玫) 